\title{
Intelligence of very preterm or very low birthweight infants in young adulthood
}

\author{
N Weisglas-Kuperus, ${ }^{1}$ E T M Hille, ${ }^{1,2}$ H J Duivenvoorden, ${ }^{3}$ M J J Finken, ${ }^{4} \mathrm{~J}$ M Wit, ${ }^{4}$ \\ S van Buuren, ${ }^{2} \mathrm{~J} B$ van Goudoever, ${ }^{1}$ S P Verloove-Vanhorick, ${ }^{2,4}$ for the Dutch POPS-19 \\ Collaborative Study Group*
}

\begin{abstract}
${ }^{1}$ Division of Neonatology, Department of Pediatrics, Erasmus MC-Sophia Children's Hospital, Erasmus University Medical Center, Rotterdam, The Netherlands; ${ }^{2}$ Businessunit Prevention and Healthcare, TNO Quality of Life, Leiden, The Netherlands; ${ }^{3}$ Erasmus MC, Department of Medical Psychology \& Psychotherapy, NIHES, Rotterdam, The Netherlands; ${ }^{4}$ Department of Pediatrics, Leiden University Medical Center, Leiden, The Netherlands
\end{abstract}

Correspondence to:

Dr N Weisglas-Kuperus, Division of Neonatology, Department of Pediatrics, Erasmus MC-Sophia Children's Hospital, Dr Molewaterplein 60, $3015 \mathrm{GJ}$ Rotterdam, The Netherlands; n.weisglas@erasmusmc.nl

*Members of the Dutch Collaborative POPS-19 Study

Group are listed in

Acknowledgements.

Accepted 3 September 2008

Published Online First

19 September 2008

\begin{abstract}
Objective: To examine the effect of intrauterine and neonatal growth, prematurity and personal and environmental risk factors on intelligence in adulthood in survivors of the early neonatal intensive care era.

Methods: A large geographically based cohort comprised 94\% of all babies born alive in the Netherlands in 1983 with a gestational age below 32 weeks and/or a birth weight $>1500 \mathrm{~g}$ (POPS study). Intelligence was assessed in 596 participants at 19 years of age. Intrauterine and neonatal growth were assessed at birth and 3 months of corrected age. Environmental and personal risk factors were maternal age, education of the parent, sex and origin.
\end{abstract}

Results: The mean (SD) I0 of the cohort was 97.8 (15.6). In multiple regression analysis, participants with highly educated parents had a 14.2-point higher I0 than those with less well-educated parents. A 1 SD increase in birth weight was associated with a 2.6-point higher 10 , and a 1 -week increase in gestational age was associated with a 1.3-point higher IO. Participants born to young mothers $1<25$ years $)$ had a 2.7-point lower I0, and men had a 2.1point higher 10 than women. The effect on intelligence after early (symmetric) intrauterine growth retardation was more pronounced than after later (asymmetric) intrauterine or neonatal growth retardation. These differences in mean 10 remained when participants with overt handicaps were excluded.

Conclusions: Prematurity as well as the timing of growth retardation are important for later intelligence. Parental education, however, best predicted later intelligence in very preterm or very low birthweight infants.

Very preterm and very low birthweight survivors are at risk of later handicap. ${ }^{1}$ Even those without obvious handicaps may have cognitive problems affecting educational achievement and professional attainment in adulthood. ${ }^{2-4}$

Gestational age at birth is related to cognitive test scores at school age. ${ }^{56}$ The immature brain is vulnerable to neonatal complications, such as germinal matrix and intraventricular haemorrhage and periventricular leucomalacia, as well as more subtle abnormalities, such as delayed myelination ${ }^{7}$ and reduced brain volume in specific cortical areas. ${ }^{8}$ These may affect later cognitive function.

Intrauterine growth retardation (IUGR) is known to have negative consequences for academic achievement and professional attainment in term born infants. ${ }^{9}$ Less is known about the effect of IUGR on cognitive outcome in preterm infants. In one study, IUGR in preterm infants was related to early developmental delay and language problems, ${ }^{10}$

\section{What is already known on this topic}

- Very preterm and very low birthweight infants are at risk of cognitive deficits at school age.

- Disability and functioning has been recently defined by the World Health Organization as a dynamic interaction between neonatal, personal and environmental factors.

- In very preterm and very low birthweight infants, the relative contributions of these factors to cognitive function in adulthood have not yet been described.

\section{What this study adds}

- Prematurity as well as the timing of growth retardation are important for later intelligence.

- Parental education, however, best predicts later intelligence in very preterm or very low birthweight infants.

and in another to more need of special education than in infants of appropriate size for gestational age (AGA). ${ }^{11}$ Weight and head circumference at birth may provide clues to the stage of fetal development at which the growth retardation occurred. Symmetric IUGR, which refers to equally poor weight and head growth, points at a process occurring early to mid pregnancy. Asymmetric IUGR, with relative head sparing, is indicative of growth retardation taking place later in pregnancy. Birth weight irrespective of head circumference predicted learning difficulties in a study of term born children. ${ }^{12}$ However, it was intrauterine head growth - and not body growth — that was the major determinant of later intelligence in preterm children. ${ }^{13}{ }^{14}$ Effects of IUGR may thus differ between term and preterm born children. In addition, during neonatal intensive care, preterm children may experience neonatal growth restraint (NGR) and subsequently display a growth pattern similar to children with IUGR. ${ }^{15}$ Postnatal rather than intrauterine growth is important for early neurodevelopmental outcome. ${ }^{16}$ The effect of NGR on later intelligence, however, is unknown.

According to the classification proposed by the World Health Organization, ${ }^{17}$ later functioning and disability are the result of a dynamic interaction between health, personal and environmental factors. 
In term born infants, environmental and personal factors such as social class at birth explain more of the variation in later cognitive function than intrauterine growth ${ }^{18}{ }^{19}$ and are important for early development in preterm infants. ${ }^{20}{ }^{21}$ The relative contributions of these risk factors on intelligence in adulthood in survivors of the early neonatal intensive care era have not yet been described.

We report a study in the Collaborative Project on Preterm and Small for Gestational Age Infants in the Netherlands (POPS), an ongoing nation-wide follow-up study on the effects of prematurity and dysmaturity on later outcome. In this large geographically based cohort, we examined the effect of neonatal conditions, such as gestational age, intrauterine and neonatal growth, as well as environmental and personal factors, such as maternal age, parental education, sex and origin, on intelligence in adulthood.

\section{SUBJECTS AND METHODS \\ Subjects}

The POPS cohort comprised $94 \%(n=1338)$ of all babies born alive in the Netherlands in 1983 with a gestational age below 32 weeks and/or a birth weight $>1500$ g. ${ }^{22}$ Of the original cohort, 379 did not survive to the age of 19: 312 died in the neonatal period (by definition the first 28 days of life), 51 in the first year of life, and 16 after the first year of life. The remaining 959 were eligible for the present study.

\section{Procedure}

Shortly after their 19th birthday, subjects were invited to participate in the study. Participation involved cognitive assessment at one of the 10 participating centres: Emma Children's Hospital AMC, Amsterdam; University Medical Center, Beatrix Children's Hospital, Groningen; University Hospital Maastricht; University Medical Center St Radboud, Nijmegen Leiden; University Medical Center, Leiden; Erasmus MC-Sophia Children's Hospital, University Medical Center Rotterdam; VU University Medical Center, Amsterdam; Wilhelmina Children's Hospital, UMC; Utrecht Máxima Medical Center, Veldhoven; Isala Clinics, Zwolle). Assessments were carried out by trained nurses; details, logistics and response rate have been reported previously. ${ }^{23}$ The respective medical ethics review boards of the 10 participating medical centres all approved the study protocol. All subjects provided written informed consent to participate in the study before assessment started.

\section{Outcome}

Intelligence was assessed with the computer version of the Multicultural Capacity Test-Intermediate Level developed by Bleichrodt. ${ }^{24}$ This recently standardised intelligence test differentiates within the lower half of the IO spectrum and measures capacity and skills of individuals with secondary education. It derives an IQ with a mean of 100 and a standard deviation of 15 in the Dutch norm sample.

\section{Risk factors}

Environmental and personal risk factors were: maternal age (in tertiles); highest education of the parents (low, primary school or junior secondary vocational education; intermediate, general or senior secondary education; high, higher vocational education or university); sex; origin (Caucasian, non-Caucasian). Neonatal factors were gestational age (in weeks) and weight (in g), length (in $\mathrm{cm}$ ) and head circumference at birth (in $\mathrm{cm}$ ) and 3 months of corrected age. Weight, length and head circumference were expressed as standard deviation scores (SDS) to adjust for (gestational) age and sex. ${ }^{25}{ }^{26}$ Subjects with a birth weight and/ or length $<-2 S D$ were labelled IUGR. Symmetric IUGR was defined as both birth size and head circumference $\leqslant-2$ SD below the mean for the infant's gestational age. Asymmetric IUGR was defined as birth size $\leqslant-2$ SD and head circumference $>-2 \mathrm{SD}$. Those with weight and length above $-2 \mathrm{SD}$ at birth as well as at 3 months were labelled AGA. Infants with weight and length above - 2SD at birth and with weight and/or length $<-2 \mathrm{SD}$ at 3 months were labelled AGA-NGR. ${ }^{15}$

\section{Statistical analysis}

Multiple imputation was applied to adjust for missing values (correcting for positive selection bias). ${ }^{23}{ }^{27}$ This simulation-based approach creates a number of imputed (completed) datasets by "filling in" plausible values for the missing data. The imputations are based on a model that uses information from other variables to achieve optimal estimates. Only imputations for the missing values between the lowest and highest values of the measured outcome variable are valid. Uncertainty about the model estimates is reflected in differences between imputations in the different completed datasets. Realistic complete data estimates can be attained by pooling results from the completed datasets. We used the MICE (multivariate imputation by chained equations) software program ${ }^{28}$ to create five imputed datasets, based on the neonatal, environmental and personal factors mentioned above and all available outcome-specific data at ages 5, 10, 14 and 19 years of age. We applied predictive mean matching to create multiple imputations. Confidence intervals for the outcomes were estimated by pooling the multiple imputations. ${ }^{29}$

Group differences for categorical variables were analysed by analysis of variance. Multiple regression analyses were performed to analyse the importance of the factors simultaneously. We assessed whether environmental and personal factors, the severity and timing of growth retardation (expressed as birth weight SDS and asymmetric IUGR, symmetric IUGR or AGANGR) and gestational age were risk factors for intelligence at 19 years of age. Analyses were performed firstly with physical and cognitive handicaps included, and secondly with handicaps excluded. The unstandardised regression coefficient (symbolised by $\mathrm{B}$ ), including $95 \% \mathrm{CI}$, and the standardised regression coefficient $(\beta)$ are presented. Data were analysed with the SPSS V12.1 software program.

\section{RESULTS}

Of the survivors, $12.6 \%$ was handicapped and had moderate to severe problems in cognitive or neurosensory functioning, ${ }^{27} 596$ of the 959 (62.1\%) participated in the assessments, ${ }^{23}$ and 562 $(94.3 \%)$ completed the intelligence test (IO) at a mean (SD) age of $19.3(0.2)$ years.

Table 1 shows the characteristics of the study group in relation to IQ. The following values are expressed as mean (SD). IQ at 19 years of age was 97.8 (15.6) (95\% CI 96.5 to 99.1); 4.3\% had an $\mathrm{IQ}<70$. Maternal age at birth was 27 (4.8) years, and gestational age was 31 (2.5) weeks. At birth, mean weight was 1314 (283) g, weight SDS was -0.9 (1.6), mean length SDS was -0.8 (1.6), and mean head circumference SDS was -0.6 (1.4). At 3 months of age, mean weight SDS was -1.3 (1.5), and mean length $-1.3(.4)$. Maternal age at birth was missing in 12 , parental education in 18, origin in six, gestational age in one, length and head circumference at birth in 134 and 80, respectively, and weight, length and head circumference at 
Table 1 Characteristics of the study group before and after multiple imputation (MI) in relation to I0 at age 19

\begin{tabular}{|c|c|c|c|c|c|}
\hline \multirow[b]{2}{*}{ Characteristic } & \multicolumn{2}{|c|}{ Before MI } & \multirow{2}{*}{$\begin{array}{l}\text { After MI } \\
(\%)\end{array}$} & \multicolumn{2}{|l|}{10} \\
\hline & No & $\%$ & & Mean (SD) & $95 \% \mathrm{Cl}$ \\
\hline \multicolumn{6}{|c|}{ Environmental and personal factors } \\
\hline \multicolumn{6}{|c|}{ Maternal age at birth (years) } \\
\hline$<25$ & 174 & 31.6 & 34.9 & $94.9(15.0)$ & 94.2 to 95.7 \\
\hline $25-30$ & 214 & 38.9 & 38.0 & $99.5(16.0)$ & 99.1 to 99.9 \\
\hline$>30$ & 162 & 29.5 & 27.1 & $99.2(15.3)$ & 98.7 to 99.6 \\
\hline \multicolumn{6}{|l|}{ Parental education } \\
\hline Low & 172 & 32.0 & 38.9 & $92.2(14.3)$ & 91.2 to 93.2 \\
\hline Intermediate & 208 & 38.2 & 36.2 & $98.6(15.0)$ & 98.2 to 99.0 \\
\hline High & 162 & 29.8 & 24.9 & $106.2(14.7)$ & 105.7 to 106.7 \\
\hline \multicolumn{6}{|l|}{ Sex } \\
\hline Male & 255 & 45.4 & 51.8 & $98.8(16.6)$ & 98.5 to 99.2 \\
\hline Female & 307 & 54.6 & 48.2 & $96.7(14.4)$ & 96.4 to 97.1 \\
\hline \multicolumn{6}{|l|}{ Origin } \\
\hline Caucasian & 496 & 89.2 & 85.3 & $98.1(15.6)$ & 97.8 to 98.3 \\
\hline Non-Caucasian & 60 & 10.8 & 14.7 & $96.5(15.2)$ & 95.8 to 97.1 \\
\hline \multicolumn{6}{|c|}{ Neonatal factors } \\
\hline \multicolumn{6}{|c|}{ Gestational age (weeks) } \\
\hline$<32$ & 413 & 73.6 & 70.5 & $98.4(15.9)$ & 98.1 to 98.7 \\
\hline$\geqslant 32$ & 148 & 28.4 & 29.5 & $96.4(14.9)$ & 96.0 to 96.9 \\
\hline \multicolumn{6}{|l|}{ Growth } \\
\hline AGA & 274 & 56.5 & 53.7 & $99.7(15.7)$ & 98.7 to 100.7 \\
\hline AGA-NGR & 79 & 16.3 & 17.3 & $95.5(15.8)$ & 93.6 to 97.4 \\
\hline Asymmetric IUGR & 46 & 9.5 & 12.1 & $97.4(14.6)$ & 96.7 to 98.1 \\
\hline Symmetric IUGR & 86 & 17.2 & 16.9 & $94.6(14.9)$ & 94.0 to 95.2 \\
\hline
\end{tabular}

AGA, appropriate size for gestational age; IUGR, intrauterine growth retardation; AGA-NGR, neonatal growth restraint.

3 months of age in 48,73 and 85 of the 562 participants, respectively. Because of colinearity, stepwise multiple regression analyses were performed for birth weight and gestational age (fig 1) and for asymmetric and symmetric IUGR and AGA-NGR (table 2) separately.

Figure 1 presents differences in mean IO for gestational age and birth weight SDS, environmental and personal factors in multiple regression analyses. A high parental education was the

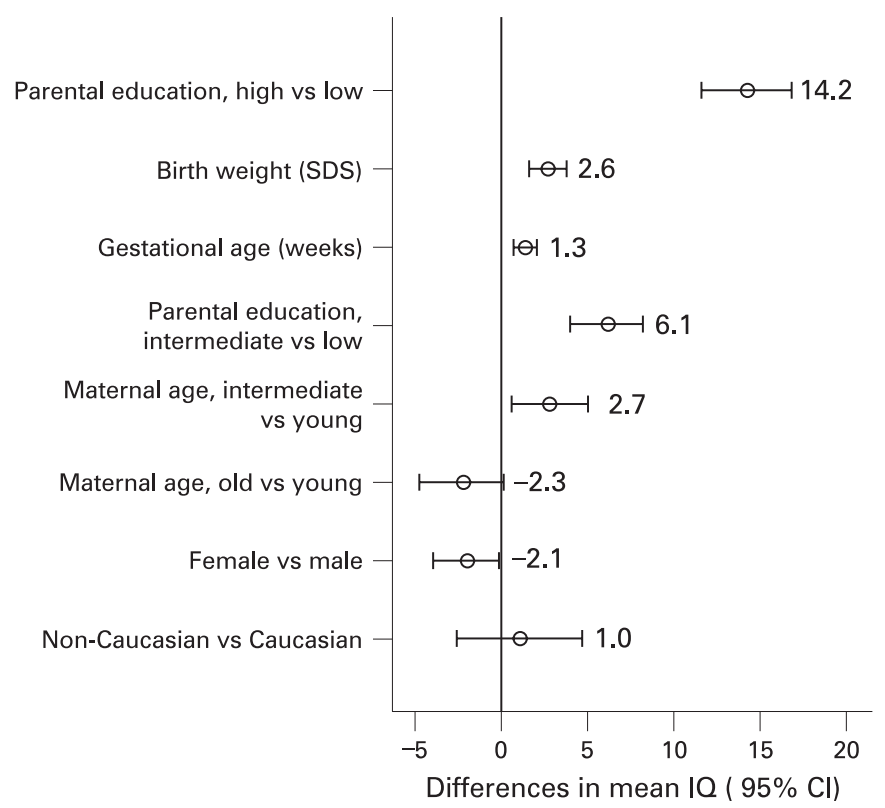

Figure 1 Differences in mean IO for gestational age and birth weight SDS and environmental and personal factors in multiple regression analyses. best predictor of IQ at 19 years of age ( $\beta 0.39$ ), followed by birth weight SDS ( $\beta$ 0.27), gestational age $(\beta 0.22)$, maternal age at birth $>25$ years $(\beta 0.08$ and 0.07 ) and sex ( $\beta$ 0.07). Participants with highly educated parents had a 14.2-point higher IO than those with less well-educated parents. A 1 SD increase in birth weight was associated with a 2.6-point higher IO, and a 1-week increase in gestational age with a 1.3-point higher IO. People with mothers aged 25-30 years at birth had a higher IO than those with younger mothers (mean difference 2.7 points). Men had a higher IO than women (mean difference 2.1 points). Comparable results were obtained when multiple regression analyses were repeated with handicaps excluded.

Table 2 presents differences in mean IO for different growth conditions corrected for environmental and personal factors in multiple regression analyses. With handicaps included, subjects born after symmetric IUGR lost 5.8 IQ points $(\beta 0.14)$, those born after asymmetric IUGR lost 3.7 IO points ( $\beta 0.08$ ), and those with NGR lost 4.1 IO points ( $\beta 0.10)$. With handicaps excluded, these losses were 5.3, 3.6 and 3.2 IQ points, ( $\beta$ 0.13, $\beta$ $0.08, \beta 0.08)$, respectively.

\section{DISCUSSION}

In our cohort, the mean IQ was 97.8 (15.6) on a very recently standardised test. This good outcome at young adulthood in these survivors from the early neonatal intensive care era is in agreement with the recent Canadian study of Saigal et $a l^{4}$ and may largely be attributable to the favourable socioeconomic circumstances. All families had access to healthcare and could benefit from the Dutch social service system, 85\% were of Caucasian origin, and parental education was high in $25 \%$. Parental education best predicted later intelligence. After adjustment for the influence of all other variables, participants with highly educated parents scored almost $1 \mathrm{SD}$ in mean IO 
Table 2 Differences in mean IQ for different growth conditions

\begin{tabular}{|c|c|c|c|c|}
\hline \multirow[b]{3}{*}{ Characteristic } & \multicolumn{4}{|l|}{10} \\
\hline & \multicolumn{2}{|l|}{ Handicaps included } & \multicolumn{2}{|l|}{ Handicaps excluded } \\
\hline & B (95\% CI) & $\beta$ & B (95\% CI) & $\beta$ \\
\hline Gestational age (weeks) & $0.5(-0.1$ to 1.0$)$ & 0.07 & $0.4(-0.1$ to 0.9$)$ & 0.07 \\
\hline \multicolumn{5}{|l|}{ Growth } \\
\hline AGA & - & - & - & - \\
\hline AGA-NGR & $-4.1(-6.6$ to -1.5$)$ & -0.10 & $-3.2(-6.3$ to -0.1$)$ & -0.08 \\
\hline Asymmetric IUGR & $-3.7(-7.1$ to -0.4$)$ & -0.08 & $-3.6(-6.7$ to -0.6$)$ & -0.08 \\
\hline Symmetric IUGR & $-5.8(-9.1$ to -2.5$)$ & -0.14 & $-5.3(-8.5$ to -2.1$)$ & -0.13 \\
\hline
\end{tabular}

The unstandardised regression coefficient $(\mathrm{B}), 95 \% \mathrm{Cl}$ and the standardised regression coefficient $(\beta)$ of the neonatal factors, adjusted for influence of environmental and personal factors in the model (eg, maternal age at birth, parental education, sex and origin).

AGA, appropriate size for gestational age; IUGR, intrauterine growth retardation; AGA-NGR, neonatal growth restraint.

points higher than those with less well-educated parents, probably reflecting genetic as well as educational influences. People whose mothers were aged 25-30 years when they were born had a higher IO than those born to younger or older mothers. This U-shaped effect of maternal age on intelligence is in line with findings from other developmental studies in nonpremature populations. ${ }^{30}$ Maternal age reflects both socioeconomic and personal age-related factors such as experience and physical endurance. In the POPS study, as in most other follow-up studies, at an early age, the handicap risk was significantly greater for boys than for girls. ${ }^{31}$ For intelligence, this male disadvantage had disappeared at 19 years of age. As we performed multiple imputations, this cannot be explained by the fact that the male subjects followed had higher maternal education and socioeconomic level than those lost to follow-up and may be catching up. Genetic conditions may account for up to $72 \%$ of the variance in intelligence. ${ }^{32}$ In children at high biological risk, however, these genetic factors may be overshadowed by environmental factors. ${ }^{33}$ In these children, an optimal environment can compensate for a cognitive delay. ${ }^{20} 21$

In our study, neonatal factors at first sight had relatively little effect on intelligence compared with parental education. One $\mathrm{SD}$ more in birth weight resulted in $2.6 \mathrm{IO}$ points more, and 1 week in gestational age resulted in $1.3 \mathrm{IO}$ points more. Compared with subjects born at 36 weeks, however, those born at 26 weeks have on average 13.0 lower IO points. Our findings in this respect are comparable to those of a meta-analysis of intelligence in school-aged children who were born very preterm, with a 10.9 mean IO point differences between the very preterm and the controls. ${ }^{5}$

The effect on intelligence in premature infants after early symmetric IUGR was more pronounced than after asymmetric IUGR. Owing to an increased risk of handicap during neonatal intensive care, however, the effect of NGR on intelligence was more serious than that of asymmetric IUGR. In this study, we were unable to differentiate small "normal" children from IUGR children. Moreover neonatal data were collected at a time when cerebral ultrasound was not routinely available. Neonatal complications such as cerebral haemorrhage or periventricular leucomalacia may result in overt handicaps that can be diagnosed at an early age. However, very preterm and very low birthweight infants develop cognitive problems in the absence of overt handicaps or neuroimaging abnormalities. ${ }^{34} 35$ To study these more subtle effects, we performed analyses in which participants with overt cognitive or neurosensory handicaps were excluded. The effect of NGR became less pronounced. Yet, the timing of the growth retardation remained a significant predictor of intelligence, suggesting that overt neonatal cerebral brain damage leading to overt handicaps does not explain these differences in IO. This study does not have the potential to identify the precise mechanisms underlying these differences in IQ. Neonatal factors contributing to neurobehavioral deficits may include the vulnerability of the immature brain both before and after birth, multiple clinical problems specific to prematurity, stressful environmental conditions, and multiple painful procedures. Moreover, neonatal hospital stay may hamper the quality of infant-parent interaction. ${ }^{36}$

We conclude that neonatal factors such as gestational age at birth and intrauterine and neonatal growth are of predictive value. The effect on intelligence after early (symmetric) IUGR is more pronounced than after later (asymmetric) intrauterine or NGR. Environmental factors, however, especially parental education, best predict later intelligence. In our study, parental education was relatively high. The good outcome at young adulthood in these survivors from the early neonatal intensive care era seems therefore to be partly due to the favourable socioeconomic circumstances of the study group growing up in Dutch society, which is representative of most Western societies. Even very preterm children with normal IQ, however, are at risk of neuropsychological deficits that may result in learning and behavioural problems. In our study compared with the general Dutch population, although the mean IO in our cohort was only $2.2 \mathrm{IO}$ points lower, twice as many young adults who had been born very preterm and/or with a very low birth weight were poorly educated ( $24 \%$ vs $12.8 \%$ ) and three times as many were neither employed nor in school $(7.6 \%$ vs $2.6 \%)$ at 19 years of age. ${ }^{27}$ Today we are witnessing an increase in the number of preterm births in many countries in the Western world. Prevention of preterm birth should therefore have high priority. An optimal environment during fetal life as well as during neonatal intensive care is warranted to prevent neonatal complications and growth restraint. After discharge, early intervention programmes should focus on the prevention of neurocognitive deficits and promote the parent-child relationship. In addition, support for children growing up in less favourable socioeconomic circumstances is needed.

Acknowledgements: We thank the young adults and their parents for their generosity in participating in our ongoing studies for the last 19 years, R Brand for his statistical advice, W Resing, $\mathrm{R}$ van den Berg and $\mathrm{N}$ Bleichrodt for their advice on the use of the MCT, and $\mathrm{J} J$ Hagoort for editing the English text.

Contributors: NW-K drafted the paper and, together with ETMH, created the study design. ETMH coordinated the data collection. NW-K, SvB and HJD analysed the data. JBVG, MJJF, JMW and SPV-Va contributed to the interpretation. SPV-V initiated and directed the POPS study as a whole and the follow-up study at age 19 in particular. All authors contributed to the drafting and revision of the manuscript.

Members of the Dutch POPS-19 Collaborative Study Group: TNO Quality of Life, Leiden (E T M Hille, C H de Groot, H Kloosterboer-Boerrigter, A L den Ouden, A Rijpstra, S P 
Verloove-Vanhorick, J A Vogelaar, coordinating centre); Emma Children's Hospital AMC, Amsterdam (J H Kok, A llsen, M van der Lans, W J C Boelen-van der Loo, T Lundqvist, H S A Heymans); University Medical Center Groningen, Beatrix Children's Hospital, Groningen (E J Duiverman, W B Geven, M L Duiverman, L I Geven, E J L E Vrijlandt); University Hospital Maastricht, Maastricht (A L M Mulder, A Gerver); University Medical Center St Radboud, Nijmegen (L A A Kollée, L Reijmers, R Sonnemans); Leiden University Medical Center, Leiden (J M Wit, F W Dekker, M J J Finken); Erasmus MC-Sophia Children's Hospital, University Medical Center Rotterdam (N Weisglas-Kuperus, M G Keijzer-Veen, A J van der Heijden, J B van Goudoever); VU University Medical Center, Amsterdam (M M van Weissenbruch, A Cranendonk, H A Delemarre-van de Waal, L de Groot, J F Samsom); Wilhelmina Children's Hospital, UMC, Utrecht (L S de Vries, K J Rademaker, E Moerman, M Voogsgeerd); Máxima Medical Center, Veldhoven (M J K de Kleine, P Andriessen, C C M Dielissen-van Helvoirt, I Mohamed); Isala Clinics, Zwolle (H L M van Straaten, W Baerts, G W Veneklaas Slots-Kloosterboer, E M J Tuller-Pikkemaat); Royal Effatha Guyot Group, Zoetermeer (M H Ens-Dokkum); Association for Parents of Premature Babies (G J van Steenbrugge)

Funding: The organisations mentioned in the acknowledgements that sponsored the study had no involvement in study design, data collection, analysis, interpretation of the data, or in the writing of the report. POPS-19 was supported by grants from the Netherlands Organization for Health Research and Development (ZonMw), Edgar Doncker Foundation, Foundation for Public Health Fundraising Campaigns, Phelps Foundation, Swart-van Essen Foundation, Foundation for Children's Welfare Stamps, TNO Quality of Life, Netherlands Organization for Scientific Research (NWO), Dutch Kidney Foundation, Sophia Foundation for Medical Research, Stichting Astmabestrijding and the Royal Effatha Guyot group. The corresponding author had full access to all data in the study and had final responsibility for the decision to submit for publication

Competing interests: None.

Ethics approval: Institutional review boards in all centres gave approval.

\section{REFERENCES}

1. Veen S, Ens-Dokkum MH, Schreuder AM, et al. Impairments, disabilities, and handicaps of very preterm and very-low-birthweight infants at five years of age. The Collaborative Project on Preterm and Small for Gestational Age Infants (POPS) in The Netherlands. Lancet 1991;338:33-6.

2. Hack M, Flannery DJ, Schluchter M, et al. Outcomes in young adulthood for verylow-birth-weight infants. N Engl J Med 2002;346:149-57.

3. Cooke RW. Health, lifestyle, and quality of life for young adults born very preterm. Arch Dis Child 2004;89:201-6.

4. Saigal S, Stoskopf B, Streiner D, et al. Transition of extremely low-birth-weight infants from adolescence to young adulthood: comparison with normal birth-weight controls. JAMA 2006;295:667-75.

5. Bhutta AT, Cleves MA, Casey PH, et al. Cognitive and behavioral outcomes of school-aged children who were born preterm: a meta-analysis. JAMA 2002;288:728-37.

6. Cooke RW. Perinatal and postnatal factors in very preterm infants and subsequent cognitive and motor abilities. Arch Dis Child Fetal Neonatal Ed 2005;90:F60-3.

7. Huppi PS, Schuknecht B, Boesch C, et al. Structural and neurobehavioral delay in postnatal brain development of preterm infants. Pediatr Res 1996;39:895-901.

8. Peterson BS, Anderson AW, Ehrenkranz R, et al. Regional brain volumes and their later neurodevelopmental correlates in term and preterm infants. Pediatrics 2003;111:939-48.

9. Strauss RS. Adult functional outcome of those born small for gestational age: twenty-six-year follow-up of the 1970 British Birth Cohort. JAMA 2000;283:625-32.

10. Gutbrod T, Wolke D, Soehne B, et al. Effects of gestation and birth weight on the growth and development of very low birthweight small for gestational age infants: a matched group comparison. Arch Dis Child Fetal Neonatal Ed 2000;82:F208-14.

11. Kok JH, den Ouden AL, Verloove-Vanhorick SP, et al. Outcome of very preterm small for gestational age infants: the first nine years of life. Br J Obstet Gynaecol 1998;105:162-8.

12. O'Keeffe MJ, O'Callaghan M, Williams GM, et al. Learning, cognitive, and attentional problems in adolescents born small for gestational age. Pediatrics 2003;112:301-7.
13. Frisk V, Amsel R, Whyte HE. The importance of head growth patterns in predicting the cognitive abilities and literacy skills of small-for-gestational-age children. Dev Neuropsychol 2002;22:565-93

14. Bergvall N, lliadou A, Johansson S, et al. Risks for low intellectual performance related to being born small for gestational age are modified by gestational age. Pediatrics 2006;117:e460-7.

15. Finken $\mathbf{M}$, Dekker $\mathbf{F}$, de Zegher $\mathbf{F}$, et al. Long-term height gain of prematurily born children with neonatal growth restraint; parallelism with the growth pattern of children born small-for-gestational-age. Pediatrics 2006;118:640-3.

16. Latal-Hajnal B, von Siebenthal K, Kovari H, et al. Postnatal growth in VLBW infants: significant association with neurodevelopmental outcome. J Pediatr 2003;143:16370.

17. World Health Organization Classification of Functioning. ICF International Classification of Functioning, Disability and Health. Geneva: World Health Organization, 2001.

18. Jefferis BJ, Power C, Hertzman C. Birth weight, childhood socioeconomic environment, and cognitive development in the 1958 British birth cohort study. BMJ 2002;325:305.

19. Sommerfelt K, Andersson HW, Sonnander K, et al. Cognitive development of term small for gestational age children at five years of age. Arch Dis Child 2000;83:25-30.

20. Fletcher JM, Landry SH, Bohan TP, et al. Effects of intraventricular hemorrhage and hydrocephalus on the long-term neurobehavioral development of preterm very-lowbirthweight infants. Dev Med Child Neurol 1997;39:596-606.

21. Weisglas-Kuperus N, Baerts W, Smrkovsky M, et al. Effects of biological and social factors on the cognitive development of very low birth weight children. Pediatrics 1993;92:658-65.

22. Verloove-Vanhorick SP, Verwey RA, Brand R, et al. Neonatal mortality risk in relation to gestational age and birthweight. Results of a national survey of preterm and very-low-birthweight infants in the Netherlands. Lancet 1986;1:55-7.

23. Hille ET, Elbertse L, Gravenhorst JB, et al. Nonresponse bias in a follow-up study of 19-year-old adolescents born as preterm infants. Pediatrics 2005;116:e662-6.

24. Bleichrodt N, Berg R. Multiculturele Capaciteiten Test Middelbaar niveau (MCT-M): Handleiding. Amsterdam: NOA, 2000.

25. Niklasson AEA, Fryer JG, Karlberg J, et al. An update of the Swedish reference standards for weight, length and head circumference at birth for given gestational age (1977-1981). Acta Paediatr Scand 1991 1991;80:756-62.

26. Fredriks AM, van Buuren S, Burgmeijer RJ, et al. Continuing positive secular growth change in The Netherlands 1955-1997. Pediatr Res 2000;47:316-23.

27. Hille $\mathbf{T}$, Weisglas-Kuperus N, van Goudoever J, et al. Functional outcomes and participation in young adulthood for very preterm and very low birth weight infants: the Dutch Project on Preterm and Small for Gestational Age Infants at 19 years of age. Pediatrics 2007;120:e587-95.

28. van Buuren S BH, Knook DL. Multiple imputation of missing blood pressure covariates in survival analysis. Stat Med 1999;18:681-94.

29. Rubin D. Multiple imputation for nonresponse in surveys. New York: John Wiley \& Sons, 1987.

30. Vreugdenhil HJ, Lanting $\mathrm{Cl}$, Mulder PG, et al. Effects of prenatal PCB and dioxin background exposure on cognitive and motor abilities in Dutch children at school age. J Pediatr 2002;140:48-56.

31. Verloove-Vanhorick SP, van Zeben-van der Aa DM, Verwey RA, et al. The male disadvantage in very low birthweight infants: does it really exist? Eur J Pediatr 1989;149:197-202.

32. Deary IJ, Spinath FM, Bates TC. Genetics of intelligence. Eur J Hum Genet 2006;14:690-700.

33. Koeppen-Schomerus G, Eley TC, Wolke D, et al. The interaction of prematurity with genetic and environmental influences on cognitive development in twins. J Pediatr 2000; 137:527-33.

34. Cooke RW, Abernethy LJ. Cranial magnetic resonance imaging and school performance in very low birth weight infants in adolescence. Arch Dis Child Fetal Neonatal Ed 1999;81:F116-21.

35. Stewart AL, Rifkin L, Amess PN, et al. Brain structure and neurocognitive and behavioural function in adolescents who were born very preterm. Lancet 1999:353:1653-7.

36. Perlman JM. Neurobehavioral deficits in premature graduates of intensive care: potential medical and neonatal environmental risk factors. Pediatrics 2001;108:1339-48. 

birthweight infants in young adulthood

N Weisglas-Kuperus, E T M Hille, H J Duivenvoorden, et al.

Arch Dis Child Fetal Neonatal Ed 2009 94: F196-F200 originally published online September 19, 2008

doi: 10.1136/adc.2007.135095

Updated information and services can be found at:

http://fn.bmj.com/content/94/3/F196.full.html

These include:

References This article cites 33 articles, 17 of which can be accessed free at: http://fn.bmj.com/content/94/3/F196.full.html\#ref-list-1

Article cited in:

http://fn.bmj.com/content/94/3/F196.full.html\#related-urls

Email alerting Receive free email alerts when new articles cite this article. Sign up in service the box at the top right corner of the online article.

Topic Articles on similar topics can be found in the following collections Collections

Pregnancy (16892 articles)

Child health (27721 articles)

Neonatal and paediatric intensive care (548 articles)

Neonatal health (2155 articles)

Neonatal intensive care (270 articles)

Notes

To request permissions go to:

http://group.bmj.com/group/rights-licensing/permissions

To order reprints go to:

http://journals.bmj.com/cgi/reprintform

To subscribe to BMJ go to:

http://group.bmj.com/subscribe/ 